\title{
The influence of Tat-derived peptide (Tat-LK15) on the uptake of membrane p- glycoproteins substrate (Calcein AM)
}

\author{
Myasar Alkotaji ${ }^{*}$, Alain Pluen ${ }^{2}$, Harmesh Aojula² \\ ${ }^{1}$ College of Pharmacy, University of Mosul, Mosul, Iraq. \\ ${ }^{2}$ School of pharmacy, University of Manchester, Manchester, UK. \\ myasar.alkotaji@uomosul.edu.iq. \\ $\underline{\text { Received }} \quad \underline{\text { Accepted }}$ \\ $\underline{1.9 .2019} \quad 1.12 .2019$
}

\begin{abstract}
Introduction: Cell penetrating peptides (CPPs) have been used in many areas of drug delivery for mediating the delivery of peptides, protein, DNA, siRNA and liposomes. Additionally they have shown an ability to overcome drug resistance in cells and enhancing chemotherapeutic activity. Our group has recently designed a promising multifunctional peptide, Tat-LK15, originating from the fusion of Tat peptide (49-57) with the synthetic amphipathic (membrane lytic) peptide, LK15. To date, Tat-LK15 peptide's effect on the cell membrane has not been assessed.
\end{abstract}

Objective: The aim of this work is to study the influence of Tat-LK15 peptide on the uptake of p-glycoproteins substrate (Calcein AM). This could explain the effect of peptide on membrane. Also this work aimed to explore whether the peptide characteristics could be exploited to improve the delivery of the cytotoxic agent, doxorubicin to doxorubicin resistant cells.

Results and discussions: Flow cytometry experiments revealed that TatLK15 peptide was not able to overcome multidrug resistance or to reverse the reduced uptake of Ca AM in the doxorubicin resistance sublines (HT29dx and K562dx). In contrast, Tat-LK15 peptide exhibited an inhibitory effect on the calcein fluorescence in both K562 and HT29 cell lines and their doxorubicin resistance sublines (HT29dx and K562dx). The supposed mechanism assumed that Tat-LK15 peptide may change phospholipid architecture/packing in the cell membrane leading to a reduction in the cell 
membrane permeability to the entry of Ca AM. Interestingly, this study indicates the possible membrane activity of Tat-LK15 peptide, which was confirmed in another work.

Keywords: Tat-LK15 peptide, p-glycoprotein substrate, cytotoxic agent, drug delivery.

\section{تأثير البيتيا المشتق من بتيذ ( Tat-15 ) على امتصاص ركيزة غثـاء بروتين سكري

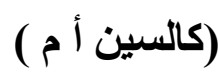

الخلاصة

الغاية من البحث : تهدف هذه الدراسة الى استكثاف ناثير البيتيد على دخول ( الكالسين أ م ) الى داخل الخلية والذي بدوره يوضح تاثير البيتيد على جدار الخلية، بالاضافع الى استغلال خاصية البيتيد لتحسين ايصال الادوية السرطانية مثل الدكسورييوسين الى الخلايا السرطانية المقاومه للدواء. طريقه العمل : استخدام ببتيدات المخترقة للخلايا في مجلات ايصال الدو اء في تطبيقات عديدة منها ايصال البيتيدات و البروتينات و العو امل الور اثية و الليبوسوم. النتائج والمناقثة : أظهرت النتائج ان البيتيد المحضر غير قادر على تجاوز مقاومة الخلايا السرطانية او لمعاكسة النقصان الحاصل على ايصال ( الكالسين ا م ) الى داخل الخلايا المقاومة لاخول عقار الدكسوريبوسين ، على العكس من ذلك اظهر البيتيد ثاثير ا مثبطا لايصال ( الكالسين ا م ) الى داخل الخلايا

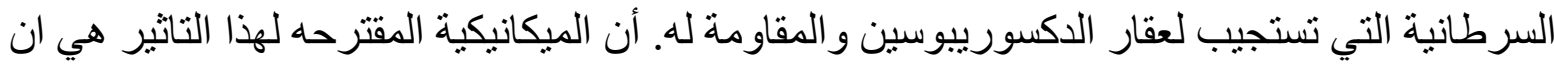
البيتيد احتمال يغيير من ترتيب او نركيب الدهون الدفسفرة في جدار الخلية.

الملخص : دراسة تاثير البيتيد على جدار الخلية السرطانية. الكلمات الدفتاحيه: البيتيد الكسين أ ، ب ـكلايكو بروتين ، الدكسوريبوسين ، مضادات السرطان ، تحرير

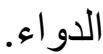


$C$ ell penetrating peptides (CPPs), which are also known as membrane translocation sequences (MTSs) or protein transduction domains (PTDs), are groups of short polypeptides (up to 30 amino acids) with the unusual ability to cross the generally impermeable biological membranes. In 1988, the full length purified Tat protein (86 amino acids) of HIV type 1 was surprisingly found to be capable of internalising into cells and activating transcription from HIV viruses. The minimal amino acid sequence responsible for the translocation ability of Tat peptide involves the highly basic, nine amino acid residues (49-57) (RKKRRQRRR) ${ }^{1}$. Tat peptide has been used successfully to deliver many different types of moieties, such as DNA, antibodies, imaging agents, toxins, siRNA, liposomes and nanoparticles. However, although several products underwent clinical trials, no Tat formulation or other CPPs formulation has succeeded to reach the market yet ${ }^{2}$. Following the principle of forming a multifunctional peptide, the ideal synthetic amphipathic peptide, LK15, was attached to Tat (49-57) peptide to produce Tat-LK15 peptide

(RKKRRQRRRGGGKLLKLLLK LLLKLLK). Tat-LK15 had previously shown improved potential for this multifunctional peptide to be used in gene delivery. Tat-LK15-DNA complex showed eleven folds enhancement in the transfection efficiency in the human connective tissue fibrosarcoma (HT1080) cell line when compared with the transfection efficiency of Tat-DNA complex ${ }^{3}$. In addition to the useful application of Tat-LK15 in DNA delivery, more recent work has demonstrated the ability of TatLK15 peptide to act as an efficient vector for small interfering RNA (siRNA) and short hairpin (shRNA) delivery. Tat-LK15 mediated high transfection efficiency of both siRNA and shRNA when targeting the BCR- 
ABL oncoprotein in chronic myeloid leukaemia cell line (K562) 4.

In principle, this improvement could be due to the improved cellular internalisation of Tat peptide. However, this peptide can affect on the cell membrane permeability to other moieties or drugs.

This work aims to explore the effect of the membrane activity of TatLK15 peptide on the cellular uptake of another molecule, i.e. calcein $\mathrm{AM}$, and at predicting the ability of Tat-LK15 to overcome doxorubicin multidrug resistance. Calcein AM $(\mathrm{Ca} \mathrm{AM})$ is considered as a membrane P-glycoprotein (P-gp) substrate that is widely used to assess the multidrug resistance in cells ${ }^{5}$. Once it enters the cells, $\mathrm{Ca}$ $\mathrm{AM}$ is converted by esterase enzymes into the fluorescent probe calcein, which is retained inside cells until membrane disruption occurs when calcein can leak outside the cell. This property was exploited to assess the membrane integrity by measuring the calcein leakage from live cells with time when exposed to supra physiological temperature ${ }^{6}$. In this study, Ca AM was used to assess the P-gp related multidrug resistance levels of doxorubicin in resistant sublines (HT29dx and K562dx) compared to the wild type cell lines (HT29 and K562). Additionally, the potential effects of Tat and Tat-LK15 peptides on the uptake of $\mathrm{Ca} \mathrm{AM}$ were investigated for different experimental conditions.

\section{Materials and methods}

Tat-LK15 peptide (RKKRRQRRRGGGKLLKLLLKL LLKLLK-CONH ${ }_{2}$ ) was synthesized by Advanced Biomedical (UK) and was 95\% pure. Tat peptide (RKKRRQRRRGGG-CONH ${ }_{2}$ ) was purchased from GL Biochem, Shanghai Ltd (China) with purity of a $90 \%$. Calcein AM was purchased from Invitrogen (UK); and verapamil were purchased from Sigma-Aldrich Ltd. (UK). Cell 
culture reagents including cell culture

media; Dulbecco's Modified Eagle Medium (DMEM), RPMI, reduced serum medium (Opti-MEM®), Lglutamine, trypsin/EDTA and penicillin/streptomycin were all purchased from Invitrogen (UK). Foetal bovine serum was purchased from BioWest (UK). Tissue culture flasks $\left(25,75\right.$ and $\left.150 \mathrm{~cm}^{2}\right)$, universal tubes (20 and $50 \mathrm{ml}$ ) and 12 and 96 well plates were obtained from Corning (USA), while phosphate buffered saline tablets (PBS tablets) were purchased from Sigma-Aldrich Ltd (UK).

\section{Assessing the interaction between peptides and the uptake of calcein AM in cancer cell lines and their doxorubicin-resistant sublines}

HT29 and HT29dx were seeded in 12 well plates one day before the experiment $\left(2 \times 10^{5}\right.$ cells per well). On the day of the experiment, the medium was removed and cells were washed with PBS. Then the cells were co-incubated with $560 \mu 1$ of Opti-MEM® ${ }^{\circledR}, 70 \mu \mathrm{l}$ of peptide and $70 \mu \mathrm{l}$ of calcein AM (the final peptide concentration was $5 \mu \mathrm{M}$ for each peptide, Tat and Tat-LK15, and the final $\mathrm{Ca} \mathrm{AM}$ concentration was $0.25 \mu \mathrm{M}$ ). After different incubation times $(5,15,45$ and 90 minutes) at $37^{\circ} \mathrm{C}$, the cells were washed twice with $0.5 \mathrm{ml}$ ice cold PBS. Then, the cells were detached by the addition of $300 \mu 1$ of $0.25 \%$ w/v trypsin/EDTA and incubated at $37^{\circ} \mathrm{C}$ for 5 minutes. Trypsinisation was stopped by adding $700 \mu \mathrm{l}$ of complete medium and the whole mixture was transferred to an Eppendorf tube, centrifuged at $73 \times$ $\mathrm{g}$ for 5 minutes. The supernatant was discarded and the pellets were re-suspended in $400 \mu 1$ of ice cold PBS and were subsequently kept on ice to be analysed within one hour by flow cytometry (Cyan, Dako, USA). For K562 and K562dx cell lines, $8 \times 10^{5}$ cells per well were seeded in a 12 well plate before the experiment, the other steps were as those carried out on adherent cells except that cells were transferred to an Eppendorf tube, then washed 
twice with $400 \mu$ lice cold PBS and then the pellets were re-suspended in $400 \mu \mathrm{l}$ ice cold PBS then kept on ice to be analysed using the flow cytometry technique. The calcein AM were excited using the 488 laser and detected using an emission band pass filter of $530 \pm 40$ nm.

Another set of experiments was conducted with preincubation of Tat-LK15 peptide for 15 minutes and subsequent addition of calcein AM for another 15 minutes. In order to quantify the contribution of $\mathrm{P}$-gp in uptake, verapamil $\mathrm{HCl}$ was used to reverse the reduction in the uptake of calcein AM in doxorubicin resistant cells ${ }^{6}$. The experiment was conducted with preincubation of $10 \mu \mathrm{M}$ verapamil $\mathrm{HCl}$ for 30 minutes and subsequent addition of $0.25 \mu \mathrm{M}$ of calcein $\mathrm{AM}$ for additional 30 minutes. All the other remaining steps were conducted as explained previously in this section.

Effect of different concentrations of Tat-LK15 peptide on calcein

\section{fluorescence}

This experiment aimed to find whether the effect of Tat-LK15 peptide on calcein AM is dependent on peptide concentration or not. Both HT29 and K562 cells were seeded as aforementioned in the previous section. On the day of the experiment, the medium was removed and cells were washed with PBS. Following this step, cells were co-incubated with $560 \mu 1$ of Opti-MEM®, $70 \mu \mathrm{l}$ of calcein AM and $70 \mu \mathrm{l}$ of peptide, the final calcein AM concentration was 0.25 $\mu \mathrm{M}$ and the final Tat-LK15 peptide concentrations were $0.1,1,2.5$ and $5 \mu \mathrm{M}$. After incubation at $37^{\circ} \mathrm{C}$ for 15 minutes, cells were treated as aforementioned then they were analysed by flow cytometry.

\section{Results}

An indirect evaluation of the influence of P-gp in different cell lines

P-gp dependent efflux in HT29dx, which is known to over-express resistance proteins (P- gp and 
MRP3) 4 (Riganti et al. 2005), and K562dx sublines were assessed by flow cytometry: $\mathrm{Ca}$ AM uptake was quantified in HT29 and K562 cell lines and in their doxorubicin resistant sublines (HT29dx and K562dx). Additionally, verapamil was used to reverse the efflux pump action of P-gp in the doxorubicin resistant sublines ${ }^{6}$.

Results presented in Figure 1 show calcein mean fluorescence intensity (MFI) represented as percentage, where calcein MFI in the wild type cells with verapamil free treatment is considered as $100 \%$. The figure represents the MFI in both K562 and K562dx (upper panel), and
HT29 and HT29dx (lower panel) in presence or absence of verapamil. A statistically significant lower uptake of $\mathrm{Ca} \mathrm{AM}$ in the doxorubicin resistant $\mathrm{K} 562 \mathrm{dx}$ and HT29dx sublines $(\mathrm{p}<0.05)$ was observed i.e. the uptake was reduced by approximately $70 \%$ in comparison to the uptake in the wild type cell lines (K562 and HT29). Remarkably, statistically significant reversals to normal uptake in both HT29dx and K562dx upon addition of verapamil were observed suggesting P-gp transporters are involved in the aforementioned reduction of $\mathrm{Ca}$ AM uptake. 


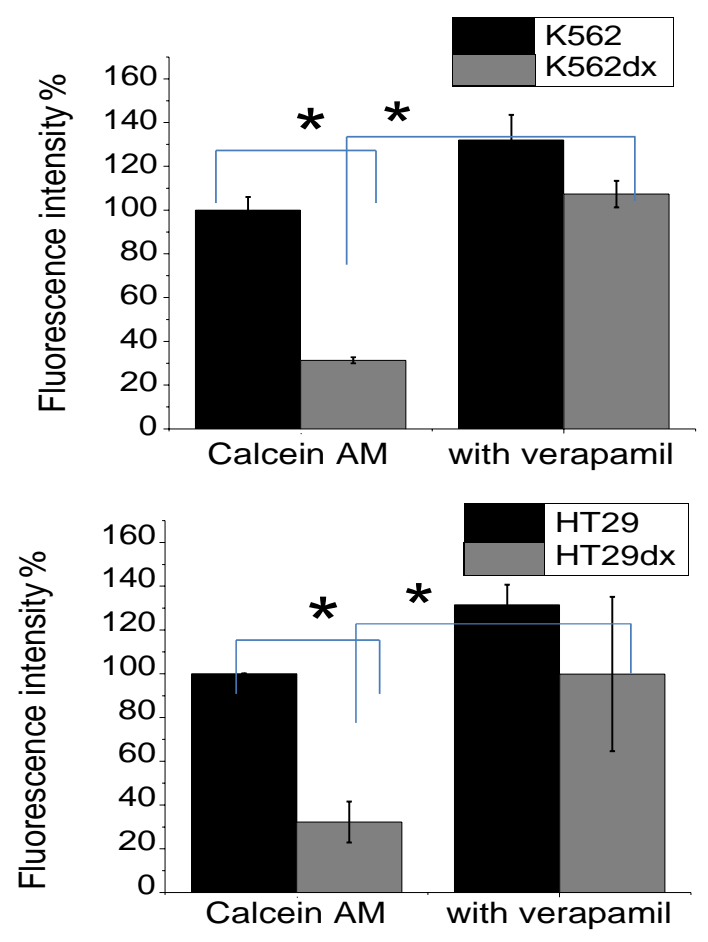

Figure 1 The detection of P-gp function in calcein accumulation and the role of verapamil

Cells were preincubated with $10 \mu \mathrm{M}$ verapamil for 30 minutes and subsequent addition of $0.25 \mu \mathrm{M}$ of $\mathrm{Ca} \mathrm{AM}$ for additional 30 minutes. Results were represented as percentages, where calcein mean fluorescence intensity (MFI) in the wild type cells with verapamil free treatment was considered as $100 \%$. The asterisk indicates a statistically significant difference $(\mathrm{p}<0.05)$.

\section{The effect of Tat and Tat-LK15 peptides on Ca AM uptake}

\section{Co-incubation with peptides}

Figure 2 A and B show representative flow cytometry histograms of K562 and HT29 cells respectively when incubated with Ca AM alone or Ca AM in the presence of Tat and Tat-LK15 peptides. The distribution of cells incubated with $\mathrm{Ca}$ AM only and those co-incubated with $\mathrm{Ca}$ AM and Tat peptide showed similar profiles; however, cells co- incubated with Ca AM and Tat-LK15 peptide showed a wider profile, which indicated a heterogeneous distribution of cells accompanied with a shift in cell distribution to lower fluorescence 
intensity levels. More quantitative data was obtained by calculating the mean fluorescence intensity of calcein and is presented in Figure $2 \mathrm{C}$ as a percentage of calcein fluorescence intensity, where calcein MFI in the cells with peptide free treatment is considered as $100 \%$ and it reflects the Ca AM uptake. Results indicate a statistically significant reduction in the calcein fluorescence in presence of Tat-LK15 peptide in both K562 and HT29 cell lines while there was no such effect when cells were co-incubated with Tat peptide.
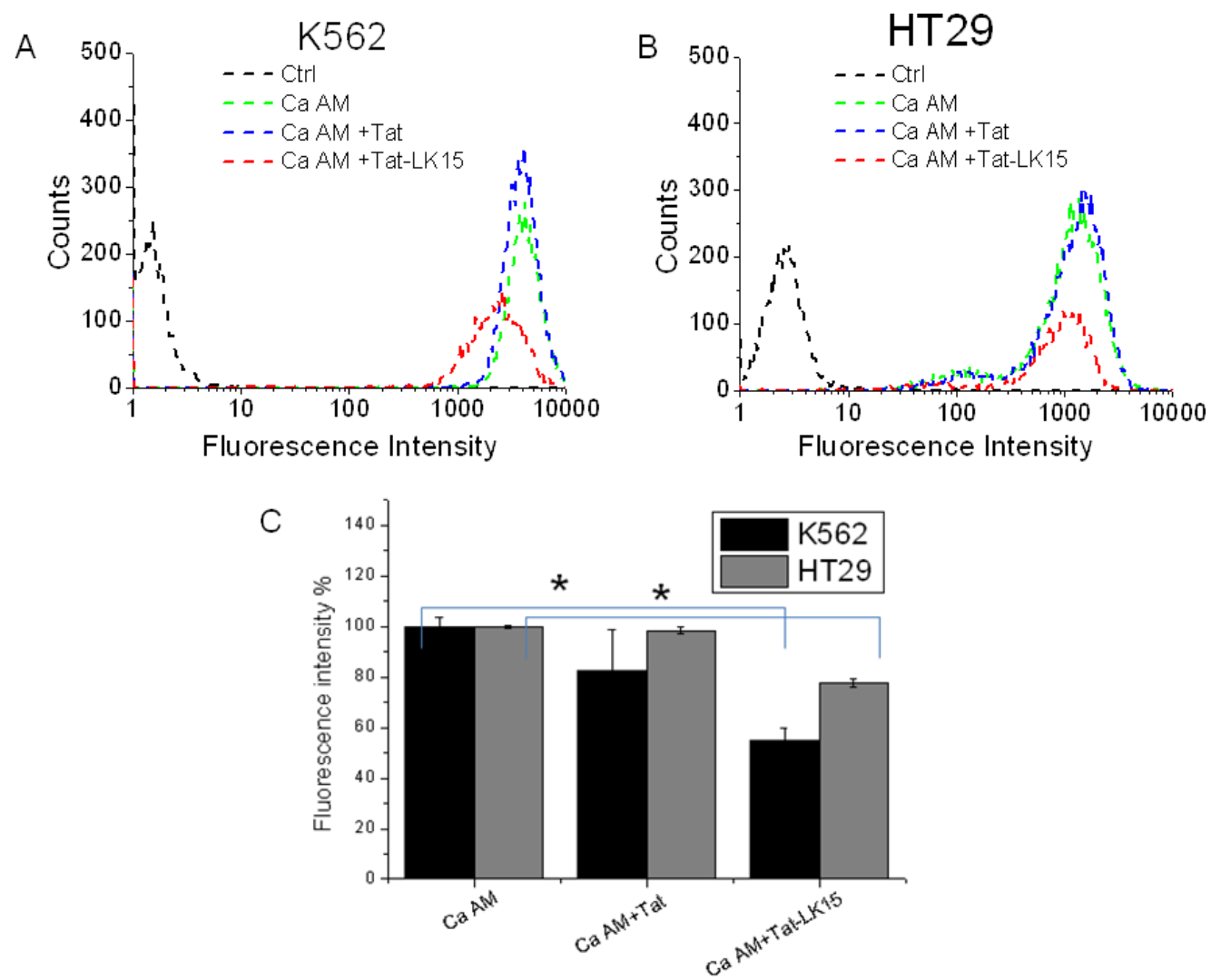

Figure 2 The effect of Tat and Tat-LK15 peptide on calcein fluorescence in K562 and HT29 cell lines when Ca AM co-incubated with peptides

K562 and HT29 cells were co-incubated with $0.25 \mu \mathrm{M}$ Ca AM and $5 \mu \mathrm{M}$ Tat or $5 \mu \mathrm{M}$ Tat-LK15 peptide for 45 minutes. Figure $2 \mathrm{~A}$ and Figure $2 \mathrm{~B}$ are representative flow cytometry histograms of K562 cells and HT29 cells respectively. Figure $2 \mathrm{C}$ is the MFI of calcein represented as percentage, where the asterisk indicates a statistically significant difference $(\mathrm{p}<0.05)$.

However, the work did not include the doxorubicin resistant sublines and did not answer the question 
whether the peptide can overcome the confirmed drug resistance in K562dx and HT29dx. Accordingly, the influence of Tat-LK15 peptide on $\mathrm{Ca}$ AM associated fluorescence was investigated on doxorubicin resistant sublines as well and for different incubation times to explore whether the recorded effect is transient or persistent after long incubation time.
HT29 and HT29dx (panel B) were co-incubated with $0.25 \mu \mathrm{M} \mathrm{Ca}$ AM and $5 \mu \mathrm{M}$ Tat-LK15 peptide for 5 , 15, 45 and 90 minutes, and then cells were prepared for flow cytometry assay of calcein fluorescence.

There is a clear sigmoidal timedependent increase in calcein fluorescence intensity in K562 and K562dx, and HT29 and HT29dx,

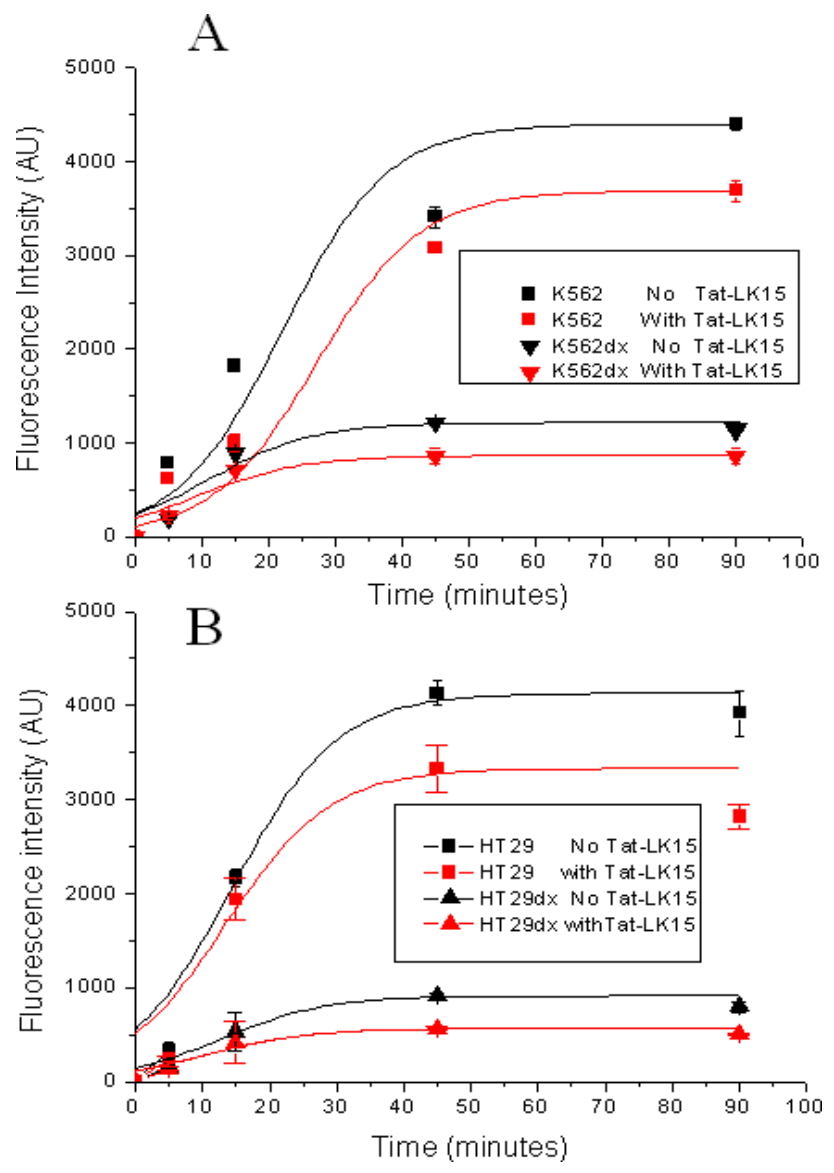

Figure 3 Calcein uptake profile in K562, HT29 cell lines and their doxorubicin resistance sublines

K562 and K562dx cells (panel A),

where the fluorescence intensity increased with time and then reached a plateau (Figure $3 \mathrm{~A}$ and Figure $3 \mathrm{~B}$ ). It is noteworthy that a 
reduction in fluorescence intensity is seen in the presence of $5 \mu \mathrm{M}$ TatLK15 peptide in both Figure 3 A and B. Notably, the reduction became more apparent after 5 minutes of co-incubation and remained even at 90 minutes of coincubation in K562 and K562dx. The MFI in K562dx cells shows the same profile as in K562 cells but with lower calcein fluorescence intensity. Similar observations can be made for HT29 and HT29dx cell lines.

Overall, it appears that only a short incubation time with cells is required for the effect of Tat-LK15 peptide to be observed. Additionally, this effect is observed in both the wild type cells and doxorubicin resistant cells to the same extent.

Pre-incubation of peptide and subsequent addition of Ca AM

In the previous experiment, an effect of the co-incubated TatLK15 peptide on calcein fluorescence was noticed. This experiment tried to find out whether Tat-LK15 peptide, upon binding to the cell membrane, could affect the uptake of Ca AM. Flow cytometry histograms (Figure $4 \mathrm{~A}$ and $\mathrm{B}$ ) show that there were slight shifts to low fluorescence intensity in cell distribution in the presence of Tat-LK15 peptide. Quantitatively, there were statistically significant reductions in calcein fluorescence in the presence of Tat- LK15 peptide in both K562 and HT29 cell lines (p < 0.05 ), while there were no such effects in the presence of Tat peptide in K562 and HT29 cell lines (see Figure $4 \mathrm{C}$ ). 

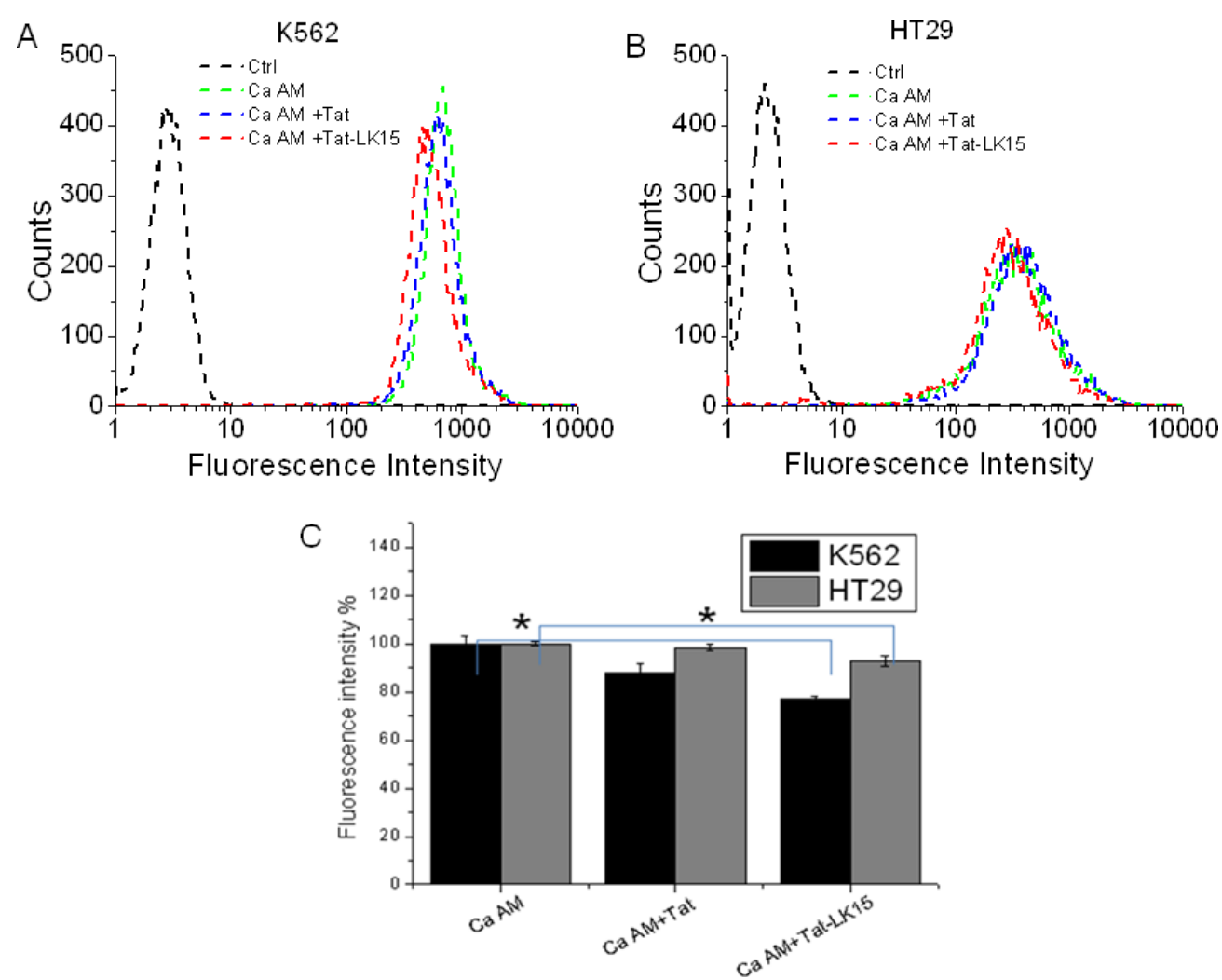

Figure 4 The pre-incubation of cells with Tat-LK15 peptide effects on the uptake of Ca AM.

Figure $5 \mathrm{~A}$ and $\mathrm{B}$ show K562 and HT29 cells were prerepresentatives flow cytometry incubated with $5 \mu \mathrm{M}$ Tat and $5 \mu \mathrm{M}$ Tat-LK15 peptides for 15 minutes and then $0.25 \mu \mathrm{M} \mathrm{Ca} \mathrm{AM}$ was added. Figure 4 A and Figure 4 B are the flow cytometry histograms of K562 cells and HT29 cells. Figure $4 \mathrm{C}$ is the MFI of calcein represented as percentage, where the asterisk indicates a statistically significant difference $(\mathrm{p}<0.05)$. histograms for the different concentrations of Tat-LK15 for K562 and HT29 cells respectively. Figure 5 A suggests a shift towards lower fluorescence intensities in K562 cells while 5 B suggests a change towards broader profiles in the presence of the peptide but a limited effect of the peptide concentration.

The inhibitory effect in the K562 cell line is Tat-LK15 concentration-dependent

Figure $5 \mathrm{C}$ presents the relative variation of the calcein MFI as a function of Tat-LK15 peptide 
concentration. An analysis of the relative calcein MFI in both K562 and HT29 cell lines reveals that there is a significant effect observed at $5 \mu \mathrm{M}$ concentration ( $\mathrm{p}$ $<0.05$ ), at which the effect was more pronounced in K562 than in HT29 cell line. Overall, there is no influence of Tat-LK15 at low concentrations, which are known to be non toxic, while at concentrations closer to the change of regimen a reduction in the relative MFI is observed.
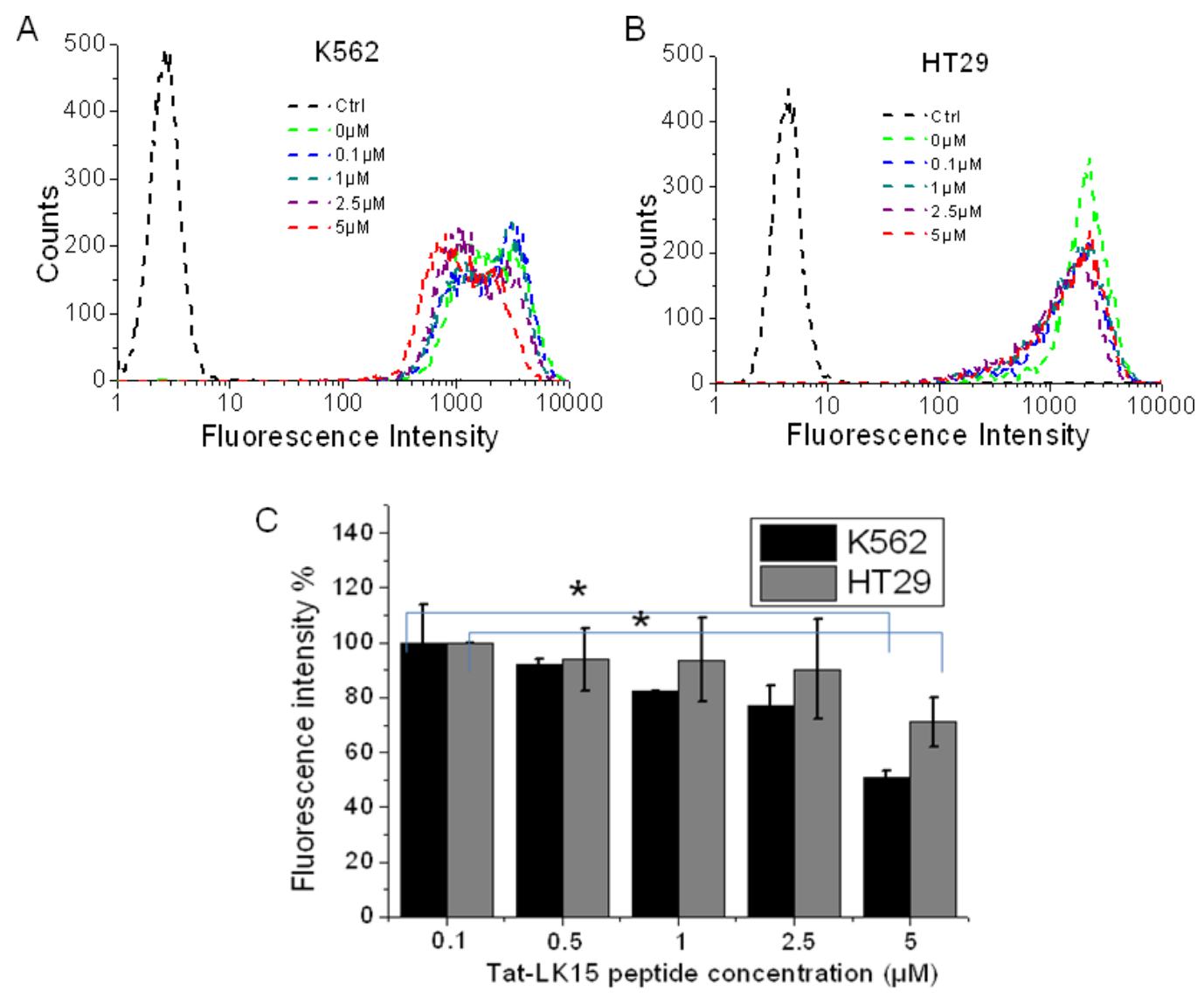

Figure 5 The effect of different concentrations of Tat-LK15 peptide on calcein fluorescence.

K562 and HT29 cells were coincubated with $0.25 \mu \mathrm{M} \mathrm{Ca}$ AM and different concentrations of TatLK15 peptide $(0.1,0.5,1,2.5$ and 5 $\mu \mathrm{M})$ for 15 minutes. Figure $\mathrm{A}$ and $\mathrm{B}$ is the flow cytometry histogram for K562 and HT29 cells respectively, while Figure $\mathrm{C}$ is the MFI of calcein represented as a percentage, where the asterisk indicates a statistically significant difference $(p<0.05)$. 


\section{Discussion}

In this study, Ca AM was used for two different purposes: (i) to assess the level of multidrug resistance in cells and (ii) to evaluate any possible effect of Tat-LK15 peptide on the uptake of a P-gp substrate.

\section{K562dx and HT29dx cell lines show characteristics of multidrug resistance}

Results show that Tat-LK15 peptide effectively resulted in lower calcein induced fluorescence levels in doxorubicin resistant cell lines (K562dx and HT29dx). Additionally, $10 \mu \mathrm{M}$ verapamil was able to reverse the reduced uptake of calcein AM in the doxorubicin resistant sublines. This validated the involvement of multidrug resistance and the P-gp membrane protein in the efflux of $\mathrm{Ca} \mathrm{AM}$ and other P-gp substrates from K562dx and HT29dx sublines. It is worthy to mention that $\mathrm{K} 562 \mathrm{dx}$ showed only partial reversal in comparison to the HT29dx cell line upon the addition of verapamil to reverse low accumulation of doxorubicin.
This is in agreement with previous work on the doxorubicin resistant subline of K562 (K562/Dox) when an incubation with $10 \mu \mathrm{M}$ verapamil was able to reverse both Rhodamine 123 (a P-gp substrate) and doxorubicin fluorescence in K562/Dox to comparable levels of its non-resistance cell line, K562 7. Additionally, the present finding with HT29dx seems to be consistent with work conducted by the group who supplied us with the doxorubicin resistance subline, where multidrug resistance was confirmed by measuring the intracellular accumulation of doxorubicin and by measuring the expression of MDR proteins in HT29dx in comparison to HT29 cells. The observed reduction in the uptake of doxorubicin in doxorubicin resistance cells was considered to be due to the efflux of doxorubicin out of the cells by the multidrug resistance proteins ${ }^{8}$.

\section{The effect of Tat and Tat-LK15 peptides on calcein AM uptake} Interestingly, the reduction in 
calcein fluorescence in K562 and HT29 cell lines was observed after a short time of co-incubation with 5 $\mu \mathrm{M}$ Tat-LK15 peptide (see Figure 3). Since $\mathrm{Ca} \mathrm{AM}$ enters cells by passive diffusion within a few minutes ${ }^{9}$, the possible explanation for the reduced calcein fluorescence may originate from the interference of Tat-LK15 peptide with the uptake of $\mathrm{Ca}$ AM.

The proposed mechanism of such interference between Tat-LK15 peptide and the uptake of $\mathrm{Ca}$ AM in cell membrane is as follows: both Tat and Tat-LK15 bind to the membrane through electrostatic interaction; however, Tat-LK15 has higher net positive charges (13 positive charges) relative to Tat peptide (8 positive charges), which may indicate possibly a stronger membrane binding of Tat-LK15 than Tat peptide. This is similar to the KLAL peptide (KLALKLALKALKAAKLA)

behaviour on lipid bilayers, where charge interactions with the lipid head groups hold the amphipathic peptide at the membrane ${ }^{10}$. TatLK15 may cover the membrane and due to its hydrophobicity and its conformational changes in the membrane ( $\alpha$-helicity), Tat-LK15 but not the Tat peptide may be inserted inside the membrane and may affect the membrane architecture by affecting the phospholipid order in the membrane which may cause loss of its permeability to $\mathrm{Ca} \mathrm{AM}$. The fact that Tat-LK15 may form aggregates at the cell membrane ${ }^{11}$ should be taken into consideration; however, there is no evidence that significant peptide aggregation could happen or even could have a role in such interaction. What could have a role is the fluidity of cell membrane, which can control the membrane permeability. Raising the temperature of the plasma membrane of mouse 3T3 fibroblasts and isolated rat skeletal muscle cells resulted in enhancing the membrane permeability and enhancing the calcein leakage out of the cells ${ }^{6}$. On the same principle, reducing the fluidity may reduce 
the

uptake; hence, the peptide might lower the membrane fluidity and permeability and may effect on the uptake of the passively diffused $\mathrm{Ca}$ AM.

The above assumed mechanism is in accordance with work conducted to explore the mechanism of action of low amphipathic, cationic, antibacterial peptides against bacteria, where lipid rearrangement inside the membrane was suggested. This mechanism assumes that binding of cationic antimicrobial agents with the membrane induces clustering of the anionic lipids into a separate domain and this causes lipid rearrangement that result in the loss of membrane function ${ }^{12}$. Such aspect of peptide membrane interaction has been studied intensely in artificial membranes or liposomes 13,14 but not in live cell membranes. According to Shai ${ }^{13}$, in order to bind to the membrane, an amphipathic peptide should point its hydrophobic face to the hydrophobic face of the membrane and it can achieve this by attaining conformational changes when being in contact with the bilayer of the membrane and then causing membrane disruption through a barrel stave or carpet like mechanism. In a similar intercalation of liposomal membranes, CM15 peptide, which is cecropin-melittin hybrid, can intercalate where such localisation requires membrane thinning and expansion of the outer leaflet of the bilayer ${ }^{14}$. In other words, the incorporation of the peptide may lead to a disruption in the membrane surface architecture.

Further supportive evidence to the role of Tat-LK15 peptide in reducing $\mathrm{Ca} A \mathrm{AM}$ uptake came from the Tat-LK15 concentrationdependent behaviour observed with the K562 cell line (see Figure 5). It is worth mentioning that in both K562 and HT29 cell lines below 5 $\mu \mathrm{M}$ concentration the effect is statistically non significant $(\mathrm{p}<$ 0.05), which in turn reflects the 
requirement of attaining a threshold concentration before such effects of the peptide can be produced. This seems to be consistent with the assumed mechanism of action of the membrane active peptide, Aurein, which is derived from frog skin. Aurein peptide causes artificial membrane lysis after attaining a threshold concentration and this lysis proceeds until reaching a sudden disruption, this action is likely to happen through a carpet like mechanism ${ }^{15}$.

One additional point that should not be neglected is that the presence of the Tat-LK15 peptide at the cell membrane might interfere with the function of the P-gp proteins, which have 12 transmembrane regions where the hydrophobic drug substrates (in this case, $\mathrm{Ca}$ AM) can bind ${ }^{16}$. However, despite the different expression patterns of P-gp in the tested cell lines (i.e. the wild type cell lines and the doxorubicin resistant cell lines), the inhibitory effect of Tat-LK15 peptide was similar. This indicates that $\mathrm{Ca} \mathrm{AM}$ efflux has no role in the observed inhibitory effect of TatLK15 peptide.

The use of an alternative technique, that can follow the kinetics of calcein leakage with time or incubating cells with high concentration of calcein instead of using $\mathrm{Ca} \mathrm{AM}$ and following the leakage might provide a more accurate answer to the mechanism of effect of peptide on cell membrane ${ }^{17}$. Nevertheless, peptide concentration is a crucial factor in inducing the ultimate pores and the subsequent complete membrane disruption or lysis. Supportive evidence for this assumption came from cecropin peptide action, at a low peptide: lipid ratio, cecropin induced a pore formation in liposomes while no measurable quantity of calcein leakage could be detected. However, at a high peptide:lipid ratio, cecropin caused calcein leakage and might breach the integrity of membrane and in case of bacteria it lead to lysis and subsequent death ${ }^{18}$. 
To summaries, Tat-LK15 peptide did not indicate any significant ability to overcome drug resistance in the doxorubicin resistant sublines. On the contrary, TatLK15 peptide showed interesting inhibitory effect on calcein fluorescence in K562 and HT29 cell lines

and their doxorubicin resistant sublines (K562dx and HT29dx). The lack of difference in effect between the wild type cells and the doxorubicin resistance cells precludes the role of $\mathrm{P}$-gp in the inhibitory effect of Tat-LK15 peptide. Considerably, this effect of Tat- LK15 is likely to be due to the reduction in uptake of $\mathrm{Ca} \mathrm{AM}$ rather than due to calcein leakage from cells. The membrane activity of Tat-LK15 relative to Tat peptide may affect the membrane lipid order in the live treated cells and induce lipid domains. This might disturb the membrane permeability to $\mathrm{Ca} \mathrm{AM}$, making it less permeable and lead to the observed inhibitory effect.

\section{References}

1- Futaki, S., T. Suzuki, et al. Arginine-rich Peptides. An abundant source of membranepermeable peptides having potential as carriers for intracellular

protein delivery. J. Biol. Chem. 2001;_276(8): 5836-5840.

2- Koren, E. and V. P. Torchilin Cell-penetrating peptides: breaking through to the other side. Trends in Molecular Medicine. 2012; 18(7): 385-393.

3- Saleh, A. F., H. Aojula, et al. Improved Tat-mediated plasmid DNA transfer by fusion to LK15 peptide. Journal of Controlled Release. 2010; 143(2): 233-242.

4- Arthanari, Y., A. Pluen, et al. Delivery of therapeutic shRNA and siRNA by Tat fusion peptide targeting bcr-abl fusion gene in Chronic Myeloid Leukemia cells. Journal of Controlled Release . 2010; 145(3): 272-280. 
cancer cells by inhibiting the drug

5- Holló, Z., L. Homolya, et al. Calcein accumulation as a fluorometric functional assay of the multidrug transporter. Biochimica et Biophysica Acta (BBA)

- Biomembranes. 1994; 1191(2): 384-388.

6- Bischof, J. C., J. Padanilam, et al. Dynamics of cell membrane permeability changes at supraphysiological temperatures. Biophysical Journal . 1995; 68(6): 2608-2614.

7- Ji, B.-S., L. He, et al. Reversal of p-glycoprotein-mediated multidrug resistance by CJX1, an amlodipine derivative, in doxorubicin-resistant human myelogenous leukemia (K562/DOX) cells. Life Sciences 2005; 77(18): 2221-2232.

8- Riganti, C., E. Miraglia, et al. Nitric oxide reverts the resistance to doxorubicin in human colon efflux. Cancer Research. 2005; 65(2): 516-525.

9- Eytan, G. D., R. Regev, et al. The role of passive transbilayer drug movement in multidrug resistance and its modulation. Journal of biological chemistry 1996; 271(22): 12897-12902.

10- Dathe, M., M. Schümann, et al. Peptide Helicity and Membrane Surface Charge Modulate the Balance of Electrostatic and Hydrophobic Interactions with Lipid Bilayers and Biological Membranes." Biochemistry 1996. 35(38): 12612-12622.

11- Alkotaji M, A. Pluen, et al. On the Cellular Uptake and Membrane Effect of the Multifunctional Peptide, TatLK15. Journal of pharmaceutical sciences.2014; (103):293-304

12- Epand, R. M. and R. F. Epand . Lipid domains in bacterial membranes and the action of 
antimicrobial agents. Biochimica et Biophysica Acta Biomembranes . 2009; 1788(1): 289-294.

13- Shai, Y. Mode of action of membrane active antimicrobial peptides. Biopolymers - Peptide Science Section. 2002; 66(4): 236-248.

14- Sato, H. and J. B. Feix. Peptide-membrane interactions and mechanisms of membrane destruction by amphipathic $\alpha-$ helical antimicrobial peptides. Biochimica et Biophysica Acta (BBA) - Biomembranes . 2006; 1758(9): 1245-1256.

15- Mechler, A., S. Praporski, et al. Specific and Selective PeptideMembrane Interactions Revealed Using Quartz Crystal Microbalance. Biophysical Journal . 2007; 93(11): 3907-3916.

16 Gottesman, M. M. Multidrug Resistance I: P-Glycoprotein.
Encyclopedia of Cancer (Second Edition). R. B. Editor-in-Chief: Press: 2002; 247254. 
Joseph. New York, Academic

17- Papo, N., A. Braunstein, et al.

Suppression of human prostate tumor growth in mice by a cytolytic D-, L-amino acid peptide: Membrane lysis, increased necrosis, and inhibition of prostatespecific antigen secretion. Cancer Research. 2004; 64(16): 57795786.

18- Silvestro, L., K. Gupta, et al. The concentration-dependent membrane activity of cecropin A. Biochemistry. 1997;_ 36(38): 11452-11460. 